\title{
Inpatient Hemodialysis Initiation: Reasons, Risk Factors and Outcomes
}

\author{
Deidra C. Crews ${ }^{a}$ Bernard G. Jaar ${ }^{a-d}$ Laura C. Plantinga ${ }^{e}$ Hania S. Kassem ${ }^{d}$ \\ Nancy E. Fink ${ }^{a, b}$ Neil R. Powe $e^{e, f}$ \\ ${ }^{a}$ Department of Medicine, Johns Hopkins University School of Medicine, ${ }^{b}$ Department of Epidemiology, \\ Johns Hopkins Bloomberg School of Public Health, 'Nephrology Center of Maryland, and dDepartment of Medicine, \\ Good Samaritan Hospital, Baltimore, Md., and ' Department of Medicine, University of California San Francisco, and \\ ${ }^{f}$ Department of Medicine, San Francisco General Hospital, San Francisco, Calif., USA
}

\section{Key Words}

End-stage renal disease $\cdot$ Hospitalization $\cdot$ Late referral $\cdot$ Mortality $\cdot$ Social support

\begin{abstract}
Background/Aims: Inpatient initiation of chronic hemodialysis is considered undesirable because of cost and possible harms of hospitalization. We examined the patient characteristics and outcomes associated with inpatient initiation. Methods: In a prospective cohort study of incident dialysis patients, the independent association of inpatient hemodialysis initiation with patient outcomes was assessed in multivariable analyses with adjustment for patient characteristics and propensity for inpatient initiation. Results: A total of 410 of $652(63 \%)$ hemodialysis patients began as inpatients; uremia and volume overload were the most commonly documented reasons. Compared to outpatients, inpatients were more likely to be unmarried, report less social support, have multiple comorbidities and be referred to a nephrologist 4 months or less prior to initiation. Inpatient initiation was protective for subsequent all-cause hospitalization (incidence rate ratio $(\mathrm{IRR})=0.92$, confidence interval $(\mathrm{Cl}) 0.89-0.94)$; this was most pronounced among those who had the highest propensity for inpatient initiation (IRR $=0.66, \mathrm{Cl} 0.56-0.78)$, including those referred late to nephrology. Similar results
\end{abstract}

were found for infectious hospitalization. Mortality [hazard ratio $=1.03, \mathrm{Cl} 0.82-1.30]$ and cardiovascular events were not significantly different for inpatients versus outpatients. Conclusion: Inpatient hemodialysis initiation has a protective association with hospitalization among those patients referred late to nephrology, with multiple comorbidities and/ or little social support.

Copyright $\odot 2009$ S. Karger AG, Basel

\section{Introduction}

Many end-stage renal disease (ESRD) patients undergo hemodialysis initiation under emergent conditions, despite evidence that early referral to nephrology is associated with improved outcomes [1-3], and planned dialysis initiation (defined as early referral to nephrology and/or dialysis initiation arranged in advance) has been associated with better patient quality of life [4-6]. Additionally, unplanned initiation of dialysis has been found

Some of the data reported here have been supplied by the United States Renal Data System. The interpretation and reporting of these data are the responsibility of the authors and in no way should be seen as an official policy or interpretation of the NCRR or NIH.

\section{KARGER}

(C) 2009 S. Karger AG, Basel

Fax +4161306 1234

E-Mail karger@karger.ch

www.karger.com
Accessible online at:

www.karger.com/nec
Deidra C. Crews, MD

Division of Nephrology, Department of Medicine

Johns Hopkins University School of Medicine

1830 E. Monument Street, Suite 416, Baltimore, MD 21205 (USA)

Tel. +1 410955 5268, Fax +1 410955 0485, E-Mail dcrews1@jhmi.edu 
to occur in both those with and without early referral to nephrology $[7,8]$. However, very few studies have elucidated other factors associated with inpatient dialysis initiation (first dialysis occurring during a hospital admission). Inpatient dialysis initiation is likely a consequence of many different factors such as comorbid disease burden, social support and health behaviors.

Conventional wisdom would argue that those initiated on dialysis as inpatients would have worse outcomes than those who started as outpatients because of poorer access to care or adherence problems, worse health status at baseline and lower socioeconomic status. However, these factors have not been well-studied. In one retrospective study conducted in Spain, it was noted that non-planned dialysis initiation (not defined as inpatient initiation, but as a lack of permanent dialysis access at initiation) was associated with increased mortality and cost compared to planned dialysis [6]. However, there is a paucity of prospective data on these and additional outcomes associated with inpatient initiation, such as hospitalizations, clinical events, transplantation and dialysis adherence. Furthermore, the clinical factors leading a physician to initiate a patient on dialysis in the inpatient setting are also not well described. There are patients in whom inpatient initiation is clearly indicated. Such patients may be too ill and unstable to initiate dialysis as outpatients. However, many patients could likely be initiated in either setting. These 2 groups of patients have not been characterized.

Our objectives were to describe the characteristics of ESRD patients initiating hemodialysis as inpatients versus outpatients, describe the reasons for inpatient initiation, and assess the outcomes of inpatient initiators as opposed to those who began dialysis as outpatients. We hypothesized that inpatient initiators would have worse outcomes than outpatient initiators.

\section{Subjects and Methods}

\section{Study Design and Population}

We examined the location (inpatient vs. outpatient) of hemodialysis initiation and associated outcomes in a national prospective cohort study of incident dialysis patients. The Choices for Healthy Outcomes in Caring for ESRD (CHOICE) study was initiated in 1995 to investigate treatment choices and outcomes of dialysis care [9]. Eligibility criteria for enrollment included establishment of long-term outpatient dialysis in the preceding 3 months, ability to provide informed consent for participation, age older than 17 years, and ability to speak English or Spanish. The Johns Hopkins University School of Medicine Institutional Review Board (IRB) and the IRBs of the participating dialysis facilities approved the study protocol.
From October 1995 to June 1998, 1,041 participants from 19 states were enrolled at 81 dialysis clinics associated with Dialysis Clinic Inc (Nashville, Tenn.; $\mathrm{n}=923$ ), New Haven CAPD (New Haven, Conn.; $\mathrm{n}=86$ ) or Saint Raphael's Hospital (New Haven, Conn.; $\mathrm{n}=32$ ). The total number of enrolled participants represents about two-thirds of eligible patients at these clinics, and those not enrolled were of similar age and gender to those who were enrolled [10]. There were 767 hemodialysis patients enrolled. For the purposes of this study, we limited our sample to a sub-cohort of hemodialysis patients with complete data on location of dialysis initiation ( $n=652$ at 71 clinics). Those with complete data had similar demographics and comorbid illness to those without.

\section{Measurements}

The location of first dialysis and documented reasons for inpatient initiation were determined retrospectively by review of the Centers for Medicare and Medicaid Services Medical Evidence Report (CMS) Form-2728 and review of clinic notes and hospital discharge summaries. Participants were considered to have been initiated as inpatients if there were documented clinical records of first dialysis during a hospitalization. They were considered to have been initiated as outpatients if there was either no hospitalization inclusive of the date of initiation of dialysis recorded on the CMS form or there were documented clinical records of first dialysis occurring during an outpatient visit. Documented reasons for inpatient initiation were those noted by the consulting nephrologist or attending physician caring for the patient during their hospitalization. Location of first dialysis and reasons for inpatient initiation were ascertained by one investigator and confirmed by a second investigator.

At enrollment, participants completed a baseline self-report questionnaire and provided demographics, medical/social history, and patient satisfaction information. Degree of social support was assessed at baseline using the Medical Outcomes Study Social Support instrument [11]. Height and weight, used to calculate body mass index (BMI), were obtained from the CMS Form2728. Late referral was defined as time between first nephrologist evaluation and start of dialysis $\leq 4$ months $[1,12]$. Vascular access was obtained through review of discharge summaries, dialysis flow and clinic notes [13].

Comorbidity, referring to medical conditions other than the primary disease itself and the severity of those conditions, was assessed using the Index of Coexistent Disease (ICED) [10, 14] score, a medical record-derived index demonstrated to predict death in dialysis populations [15]. ICED scores range from 0 to 3 with 3 as the highest severity level. A trained research nurse abstracted medical records to determine these scores, based on 19 medical conditions. Individual comorbidities were abstracted from dialysis clinic records, hospital discharge summaries, medication lists, consultation notes, diagnostic imaging and cardiac imaging reports, which were collected at each dialysis unit, and sent to the New England Medical Center for abstraction and scoring. Reliability of data abstraction and severity scoring was assessed by masked recoding of 45 medical records [15]. Interrater reliability for ICED scoring was high $(\kappa=0.93)$.

Baseline non-fasting venous blood specimens were routinely collected at the Dialysis Clinic, Inc. facilities just prior to a dialysis session. Laboratory values for albumin, creatinine, potassium, calcium, phosphorus and hemoglobin were obtained from month- 
ly laboratory tests at dialysis clinics, and average values for the first 3 months on dialysis therapy were calculated. Total cholesterol levels were obtained from aliquoted samples sent to Quest Diagnostics (Baltimore, Md., USA). The glomerular filtration rate (GFR) before dialysis initiation was estimated by the 6-variable Modification of Diet in Renal Disease (MDRD) equation using creatinine values obtained from CMS Form-2728 [16]. Calcium levels were corrected for albumin before calcium-phosphate products were calculated. Hemodialysis dosage (Kt/V) was calculated using values of blood urea nitrogen, pre- and post-dialysis weight, and dialysis duration by the Daugirdas formula [17].

\section{Outcomes Ascertainment}

The observation period for each participant began on the date of enrollment and continued until 31 December 2004. Median follow-up was 3.0 years (range $\sim 1$ week to 9.1 years). The primary outcomes of interest were mortality and hospitalization rates. Mortality information was ascertained from clinic report, medical records, CMS, and the National Death Index. Follow-up for mortality continued until death, transplantation or the last follow-up date. All-cause, infectious, and cardiovascular hospitalization data were obtained from the United States Renal Data System (USRDS). Infectious hospitalization ascertainment using the International Classification of Diseases, 9th revision has been previously described in CHOICE [18]. Cardiovascular events were obtained by the Cardiovascular Disease Endpoints Committee - trained physicians who reviewed the hospital records to determine cause of hospitalization using uniformly applied criteria modified from the Cardiovascular Health Study [19] and the HEMO study [20]. Adjudicated events included myocardial infarction, cerebrovascular accident, and the following procedures: abdominal aortic aneurysm repair, percutaneous transluminal coronary angioplasty, coronary artery bypass graft, carotid endarterectomy, peripheral bypass of the lower extremity, and amputations (excluding digit amputations).

Secondary outcomes of interest were transplantation, dialysis adherence and patient-reported satisfaction. Transplantation was ascertained from clinic reports and United States Renal Data System. Dialysis adherence measures were ascertained from clinic attendance records and serum potassium and serum phosphate obtained during follow-up. Participants were considered adherent with their dialysis treatment schedule if they skipped less than or equal to $3 \%$ of their overall scheduled sessions; a cutoff value that has been previously related to patient-physician contact $[21$, $22]$. Goal potassium at 1 year of follow-up was defined as $\leq 5.0$ $\mathrm{mEq} / \mathrm{l}$, and that of phosphorus was defined as $<5.5 \mathrm{mg} / \mathrm{dl}$ [22]. Patient satisfaction was assessed using global questions of overall quality of dialysis care and whether or not participants would recommend their dialysis center [23].

\section{Statistical Analysis}

Baseline characteristics of the sample stratified by location of dialysis initiation were compared using $\chi^{2}$ tests for categorical variables and t tests for continuous variables. Cox-proportional hazards regression was used to test the association between location of dialysis initiation and mortality. Survival time was calculated from the date of first dialysis until death. Patients were censored if they received a transplant. Poisson regression with overdispersion was used to test the association between location of dialysis initiation and subsequent hospitalizations. Time to trans- plantation was modeled using Cox proportional hazards regression, and dialysis adherence measures and patient satisfaction (extremely satisfied vs. less than extremely satisfied) were modeled using logistic regression.

Potential confounders were identified by assessing the relationships between each variable and inpatient dialysis initiation and between the variable and the outcome $(p<0.20$ for both associations). Also, clinically relevant variables that did not meet these criteria were still included in the multivariable model. Based on these criteria, confounders included in the aforementioned models were age, sex, race, marital status, smoking history, affectionate social support, ICED score, BMI, nephrology referral time, and serum albumin. Multiple imputation was used to address covariates with more than $3 \%$ missing data (assumed to be missing at random [24]). These were nephrology referral time (17.9\% missing) and affectionate social support (6.3\% missing). Subgroup analyses by race and nephrology referral time were tested, given prior evidence of differential mortality for blacks and whites on dialysis [25] and previously reported poor outcomes for dialysis patients referred late to nephrology [1]. In these analyses, only complete (non-imputed) data were used.

Several sensitivity analyses were performed. First, Poisson regression models for infectious hospitalization were examined with and without dialysis access at baseline as a covariate. Second, change in comorbid disease over time and dialysis adherence measures were examined to determine if they could account for differences in primary outcomes between inpatient and outpatient initiators. Third, an interaction term for race and nephrology referral time was tested, given a prior study of this cohort found black race to be associated with late referral [1]. Fourth, to examine the possibility of survival bias, the time from dialysis initiation to enrollment in CHOICE was evaluated in primary outcome models. Fifth, propensity scores were calculated, and baseline characteristics by propensity score tertile were compared using the aforementioned methods. Additionally, propensity score adjusted models were analyzed after using logistic regression to calculate the estimated probability of a patient being initiated on hemodialysis as an inpatient [26]. The following variables were used to derive this propensity score for each patient: age, sex, race, marital status, smoking history, affectionate social support, ICED score, BMI, nephrology referral time, and serum albumin. Finally, to examine the possibility of selection bias (i.e. some deaths were missed during the enrollment period), a simulated analysis using data from the propensity scores was performed to estimate the effect of the absence of these patients. We added 20 additional hypothetical deaths in the first 90 days of follow-up. The covariates used in this analysis were estimated from the median values of those with the highest propensity to be inpatients.

In all analyses, the possibility of confounding by dialysis clinic was controlled with fixed-effects modeling, clustered on clinic, which accounted for within-clinic correlation and between-clinic differences in outcomes [27]. A 2-sided $p<0.05$ was used as the level of significance for all tests. Statistical analyses were performed using Stata software, version 10 (Stata Corporation, College Station, Tex., USA). 
Fig. 1. Documented reasons for inpatient dialysis initiation $(\mathrm{n}=410)$. Reasons for the remaining $11.0 \%$ (45 of 410 ) were various combinations of those noted in this figure. ${ }^{1}$ Uremia includes symptoms such as nausea/vomiting, fatigue, anorexia, metallic taste and pruritus. ${ }^{2}$ Other documented reasons included: progressive renal failure, status-post cardiac catheterization, and status-post cardiac surgery. ${ }^{3} \mathrm{HTN}=$ Hypertension.

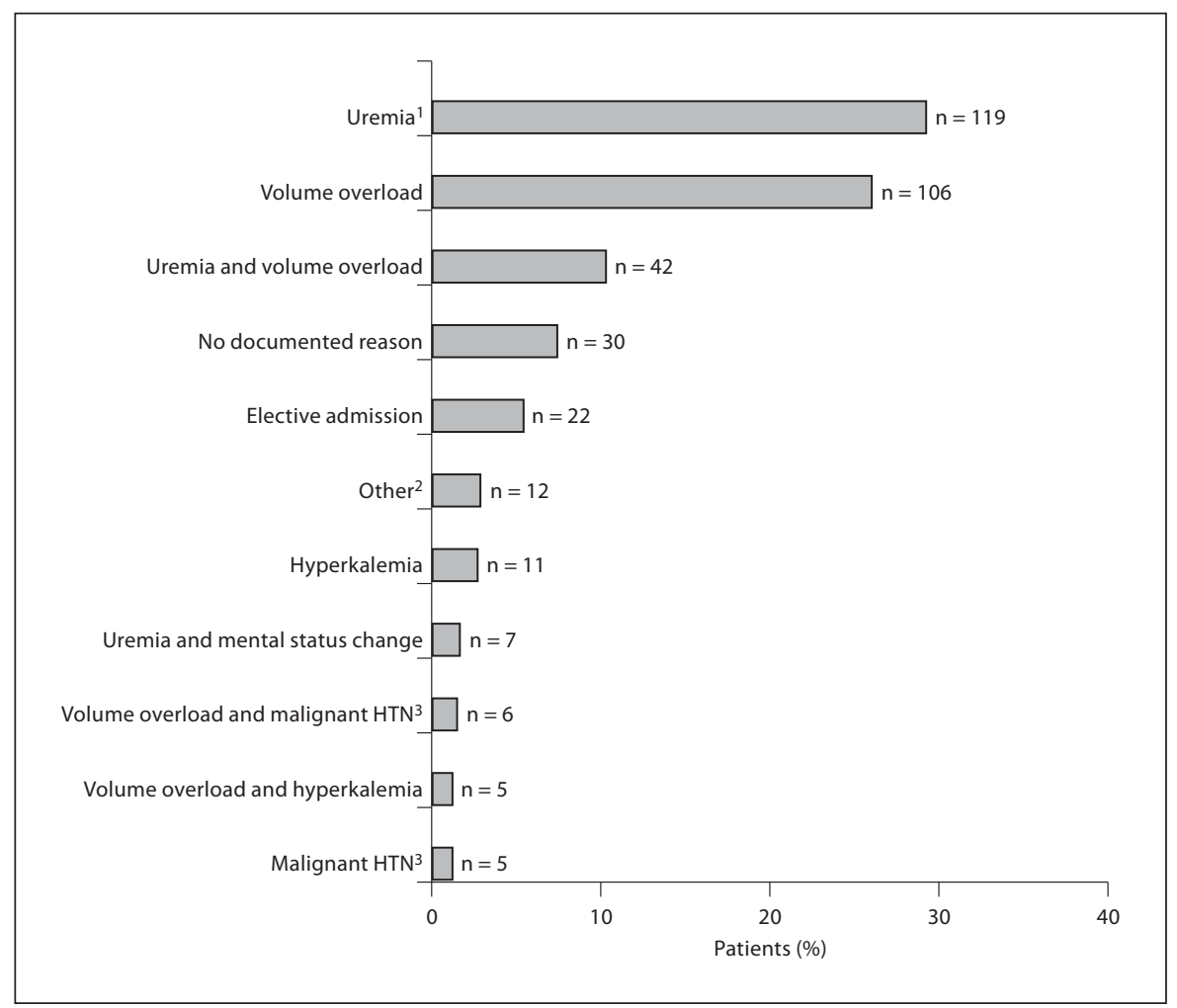

\section{Results}

\section{Patient Characteristics and Reasons for Inpatient Initiation}

The majority of patients, 410/652 (63.0\%), were first dialyzed during a hospitalization (table 1), based on review of dialysis clinic notes and hospital discharge summaries. In contrast, only 41 (10\%) inpatients were noted on CMS Form-2728 to have a primary dialysis setting of 'hospital inpatient'. Median time from dialysis initiation to study enrollment was 52 days for inpatients and 47 days for outpatients $(p=0.053)$. Compared to outpatient initiators, inpatients were more likely to be unmarried, report less social support, be former or current smokers, have multiple comorbidities and be referred late to nephrology. Late nephrology referral was a strong predictor of inpatient initiation [odds ratio (OR), 2.0, 95\% confidence interval (CI) 1.3-3.1] in multivariable regression analysis. Analysis by propensity score tertile revealed those in the third tertile (highest propensity for being an inpatient) to be least likely to be employed, least likely to be married or report adequate social support, and most likely to have used tobacco and/or drugs. This tertile also had the greatest comorbid disease burden. Uremia, volume overload, and their combination were the most commonly documented reasons for inpatient initiation; and few patients were documented to have been electively admitted for dialysis initiation (fig. 1).

\section{Mortality and Hospitalization}

Compared to those initiated on dialysis as outpatients, the overall risk of death was not significantly different among inpatients (table 2). In unadjusted analysis, inpatient initiation was not significantly associated with subsequent all-cause hospitalizations, but there was an $8 \%$ lower rate of hospitalization among inpatients versus outpatients in adjusted analysis [incidence rate ratio (IRR), 0.92, 95\% confidence interval (CI) 0.89-0.94]. Similarly, in adjusted analysis, there was a $14 \%$ lower rate of infectious hospitalization among inpatient initiators (IRR, 0.86, 95\% CI 0.83-0.89). The differences between the unadjusted and adjusted hospitalization models were in large part due to confounding by greater comorbid disease among inpatient initiators. There was no difference in incident cardiovascular events between the 2 groups. 
Table 1. Baseline characteristics of participants by location of dialysis initiation

\begin{tabular}{|c|c|c|c|c|c|c|c|}
\hline Characteristic & $\begin{array}{l}\text { Outpatient } \\
\text { initiation }\end{array}$ & $\begin{array}{l}\text { Inpatient } \\
\text { initiation }\end{array}$ & $\mathrm{p}$ & $\begin{array}{l}\text { Inpatient } \\
\text { propensity } \\
\text { tertile } 1\end{array}$ & $\begin{array}{l}\text { Inpatient } \\
\text { propensity } \\
\text { tertile } 2\end{array}$ & $\begin{array}{l}\text { Inpatient } \\
\text { propensity } \\
\text { tertile } 3\end{array}$ & $\begin{array}{l}\mathrm{p} \text { for } \\
\text { trend }\end{array}$ \\
\hline Total & $242(37.0)$ & $410(63.0)$ & - & 218 & 217 & 217 & - \\
\hline \multicolumn{8}{|l|}{ Demographics } \\
\hline Age in years, mean (SD) & $59.2 \pm 13.7$ & $59.7 \pm 15.4$ & 0.700 & $58.2 \pm 14.3$ & $59.5 \pm 15.5$ & $60.8 \pm 15.4$ & 0.067 \\
\hline Male & $130(53.7)$ & $218(53.2)$ & 0.892 & $117(53.7)$ & $113(52.1)$ & $118(54.4)$ & 0.883 \\
\hline Black race & $79(32.6)$ & $129(31.5)$ & 0.456 & $77(35.3)$ & $70(32.3)$ & $61(28.1)$ & 0.107 \\
\hline Insured & $230(95.0)$ & $385(93.9)$ & 0.544 & 207 (94.9) & $203(93.6)$ & $205(94.5)$ & 0.827 \\
\hline Employed & $21(8.7)$ & $34(8.3)$ & 0.852 & $30(13.8)$ & $15(6.9)$ & $10(4.6)$ & 0.001 \\
\hline Education $\geq$ high school & $158(67.8)$ & $254(64.5)$ & 0.394 & $142(68.6)$ & 133 (63.9) & $137(64.6)$ & 0.394 \\
\hline Married & $147(60.5)$ & $199(49.6)$ & 0.004 & $166(76.5)$ & $106(49.8)$ & $74(34.4)$ & $<0.001$ \\
\hline \multicolumn{8}{|l|}{ Health behaviors } \\
\hline Smoking, current or former & $126(52.1)$ & $256(62.4)$ & 0.009 & $75(34.4)$ & $142(65.4)$ & $165(76.0)$ & $<0.001$ \\
\hline Alcohol use, current & $21(9.2)$ & $28(7.2)$ & 0.398 & $117(88.6)$ & $133(91.7)$ & $142(86.6)$ & 0.523 \\
\hline Illicit drug use, current or former & $34(14.8)$ & $65(17.1)$ & 0.464 & $22(10.8)$ & $34(17.1)$ & $43(20.8)$ & 0.007 \\
\hline \multicolumn{8}{|l|}{ Comorbidities } \\
\hline Hypertension & $220(90.9)$ & $374(91.2)$ & 0.893 & $202(92.7)$ & $201(92.6)$ & $191(88.0)$ & 0.148 \\
\hline Diabetes & $103(42.6)$ & $177(43.2)$ & 0.879 & $91(41.7)$ & $105(48.4)$ & $84(38.7)$ & 0.525 \\
\hline Overweight or obesity $(\mathrm{BMI}>25)$ & $163(67.4)$ & $233(56.8)$ & 0.008 & $179(82.1)$ & $134(61.8)$ & $83(38.3)$ & $<0.001$ \\
\hline COPD & $20(8.3)$ & $55(13.4)$ & 0.046 & $17(7.8)$ & $19(8.8)$ & $39(18.0)$ & 0.001 \\
\hline Cardiovascular disease $^{\mathrm{a}}$ & $131(54.1)$ & $258(62.9)$ & 0.027 & $117(53.7)$ & $132(60.8)$ & $140(64.5)$ & 0.021 \\
\hline Congestive heart failure & $26(10.7)$ & $53(12.9)$ & 0.409 & $20(9.2)$ & $20(9.2)$ & $39(18.0)$ & 0.005 \\
\hline Left ventricular hypertrophy & $45(18.6)$ & $133(32.4)$ & $<0.001$ & $49(22.5)$ & $60(27.7)$ & $69(31.8)$ & 0.030 \\
\hline ICED score $(0-3)$, mean (SD) & $1.9 \pm 0.75$ & $2.1 \pm 0.80$ & 0.003 & $1.6 \pm 0.61$ & $2.0 \pm 0.77$ & $2.4 \pm 0.76$ & $<0.001$ \\
\hline \multicolumn{8}{|l|}{ Clinical measures, mean (SD) } \\
\hline Serum phosphate, mg/dl & $5.4 \pm 1.4$ & $5.3 \pm 1.3$ & 0.122 & $5.4 \pm 1.3$ & $5.3 \pm 1.2$ & $5.3 \pm 1.3$ & 0.195 \\
\hline Serum calcium, mg/dl & $9.0 \pm 0.7$ & $9.2 \pm 0.7$ & 0.987 & $9.1 \pm 0.66$ & $9.1 \pm 0.70$ & $9.1 \pm 0.67$ & 0.868 \\
\hline Calcium-phosphate product & $50.1 \pm 12.6$ & $49.8 \pm 12.5$ & 0.389 & $50.8 \pm 12.7$ & $49.3 \pm 11.6$ & $49.8 \pm 13.1$ & 0.369 \\
\hline Serum potassium, mEq/l & $4.5 \pm 0.6$ & $4.6 \pm 0.6$ & 0.984 & $4.5 \pm 0.54$ & $4.5 \pm 0.55$ & $4.6 \pm 0.61$ & 0.038 \\
\hline Hemoglobin, g/dl & $10.5 \pm 1.2$ & $10.7 \pm 1.2$ & 0.909 & $10.6 \pm 1.1$ & $10.5 \pm 1.3$ & $10.7 \pm 1.2$ & 0.195 \\
\hline Serum albumin, $\mathrm{g} / \mathrm{dl}$ & $3.7 \pm 0.4$ & $3.6 \pm 0.4$ & 0.204 & $3.7 \pm 0.35$ & $3.7 \pm 0.34$ & $3.6 \pm 0.37$ & 0.019 \\
\hline Serum total cholesterol, mg/dl & $187 \pm 43$ & $184 \pm 46$ & 0.237 & $190 \pm 49$ & $181 \pm 45$ & $183 \pm 41$ & 0.099 \\
\hline Estimated $\mathrm{GFR}^{\mathrm{b}}, \mathrm{ml} / \mathrm{min} / 1.73 \mathrm{~m}^{2}$ & $9.2 \pm 3.4$ & $8.9 \pm 3.0$ & 0.130 & $8.7 \pm 3.3$ & $8.9 \pm 2.9$ & $9.4 \pm 3.1$ & 0.056 \\
\hline \multicolumn{8}{|l|}{ Renal care } \\
\hline Late nephrology referral ( $\leq 4$ months $)^{c}$ & $46(22.2)$ & $128(39.0)$ & $<0.001$ & $9(4.9)$ & $44(25.1)$ & $121(68.4)$ & $<0.001$ \\
\hline Catheter for initial vascular access ${ }^{c}$ & $82(48.5)$ & $213(76.6)$ & $<0.001$ & $95(62.1)$ & $91(59.1)$ & $109(77.9)$ & 0.006 \\
\hline $\mathrm{Kt} / \mathrm{V}$, mean $(\mathrm{SD})$ & $1.24 \pm 0.28$ & $1.28 \pm 0.31$ & 0.232 & $1.20 \pm 0.29$ & $1.29 \pm 0.30$ & $1.31 \pm 0.30$ & 0.001 \\
\hline \multicolumn{8}{|l|}{ Social support, $\mathrm{n}(\%)$ achieving median } \\
\hline Emotional support & $110(47.8)$ & $179(46.7)$ & 0.386 & $109(52.7)$ & $98(48.8)$ & $82(39.8)$ & 0.009 \\
\hline Tangible support & $106(45.7)$ & $174(44.6)$ & 0.398 & $108(51.9)$ & $89(43.6)$ & $83(39.5)$ & 0.011 \\
\hline Affectionate support & $120(52.9)$ & $168(43.8)$ & 0.015 & $126(61.2)$ & $92(46.0)$ & $70(34.2)$ & $<0.001$ \\
\hline Social interaction & $112(48.7)$ & $157(40.9)$ & 0.030 & $113(54.6)$ & $85(42.3)$ & $71(34.5)$ & $<0.001$ \\
\hline
\end{tabular}

Univariate analysis. To convert phosphate in $\mathrm{mg} / \mathrm{dl}$ to $\mathrm{mmol} / \mathrm{l}$, multiply by 0.3229 ; calcium in $\mathrm{mg} / \mathrm{dl}$ to $\mathrm{mmol} / \mathrm{l}$, multiply by 0.2495 ; potassium in $\mathrm{mEq} / \mathrm{l}$ to $\mathrm{mmol} / \mathrm{l}$, multiply by 1 ; hemoglobin and albu$\mathrm{min}$ in $\mathrm{g} / \mathrm{dl}$ to $\mathrm{g} / \mathrm{l}$, multiply by 10 ; cholesterol in $\mathrm{mg} / \mathrm{dl}$ to $\mathrm{mmol} / \mathrm{l}$, multiply by 0.02586 . Figures in parentheses are percentages.

$\mathrm{COPD}=$ Chronic obstructive pulmonary disease; $\mathrm{Kt} / \mathrm{V}=$ clearance of urea $(\mathrm{K})$ multiplied by $(\mathrm{t})$ per volume $(\mathrm{V})$ of patient's total body water.
${ }^{a}$ Cardiovascular disease includes cerebrovascular and peripheral vascular disease. ${ }^{b}$ Estimated GFR was calculated with the 6-variable MDRD formula, using the initial laboratory values reported on CMS Form-2728. ${ }^{\mathrm{c}}$ Nephrology referral time, $\mathrm{n}=535$ and vascular access, $\mathrm{n}=447$. 
Table 2. Clinical outcomes by location of dialysis initiation

\begin{tabular}{|c|c|c|c|c|c|c|}
\hline \multirow[t]{3}{*}{ Outcome measure } & \multirow{3}{*}{$\begin{array}{l}\text { Inpatient } \\
\text { initiation } \\
(\mathrm{n}=410)\end{array}$} & \multirow{3}{*}{$\begin{array}{l}\text { Outpatient } \\
\text { initiation } \\
(\mathrm{n}=242)\end{array}$} & \multicolumn{4}{|c|}{ Relative risk of inpatient vs. outpatient (referent) ${ }^{\mathrm{a}}(95 \% \mathrm{CI})$} \\
\hline & & & \multirow[t]{2}{*}{ unadjusted } & \multirow{2}{*}{$\begin{array}{l}\text { multivariable } \\
\text { adjusted }^{\text {b }}\end{array}$} & \multicolumn{2}{|c|}{ propensity score adjusted $^{c}$} \\
\hline & & & & & $\begin{array}{l}\text { tertiles } 1 \text { and } 2 \\
(\mathrm{n}=435)\end{array}$ & $\begin{array}{l}\text { tertile } 3 \\
(\mathrm{n}=217)\end{array}$ \\
\hline 1-Year mortality, n (\%) & $49(12.0)$ & $26(10.7)$ & $1.10(0.66-1.84)$ & $0.91(0.76-1.09)$ & $0.74(0.38-1.44)$ & $2.19(0.63-7.66)$ \\
\hline Overall mortality, n (\%) & $285(69.5)$ & $151(62.4)$ & $1.16(0.93-1.44)$ & $1.03(0.82-1.30)$ & $1.02(0.78-1.33)$ & $0.96(0.61-1.53)$ \\
\hline All-cause hospitalization ${ }^{\mathrm{d}}$ & 1.63 & 1.67 & $0.94(0.87-1.01)$ & $0.92(0.89-0.94)$ & $0.96(0.88-1.05)$ & $0.66(0.56-0.78)$ \\
\hline Infectious hospitalization $^{\mathrm{d}}$ & 0.78 & 0.75 & $0.90(0.81-1.00)$ & $0.86(0.83-0.89)$ & $0.93(0.82-1.05)$ & $0.65(0.51-0.82)$ \\
\hline Incident cardiovascular events, $\mathrm{n}(\%)$ & $249(60.7)$ & $134(55.4)$ & $1.10(0.88-1.39)$ & $1.03(0.95-1.11)$ & $1.04(0.78-1.37)$ & $0.93(0.55-1.57)$ \\
\hline Transplantation, $\mathrm{n}(\%)$ & $75(18.3)$ & $56(23.1)$ & $0.82(0.52-1.29)$ & $0.93(0.78-1.11)$ & $0.90(0.52-1.57)$ & $3.26(0.35-30.1)$ \\
\hline \multicolumn{7}{|l|}{ Dialysis adherence measures, $\mathrm{n}(\%)$} \\
\hline Serum potassium $\leq 5.0 \mathrm{mEq} / \mathrm{l}$ & $25(7.86)$ & $30(15.3)$ & $0.47(0.24-0.90)$ & $0.41(0.23-0.71)$ & $0.43(0.21-0.87)$ & $0.43(0.16-1.21)$ \\
\hline Serum phosphorus $\leq 5.5 \mathrm{mg} / \mathrm{dl}$ & $170(53.5)$ & $102(52.3)$ & $1.05(0.75-1.47)$ & $1.03(0.68-1.58)$ & $0.83(0.49-1.41)$ & $1.26(0.55-2.87)$ \\
\hline Dialysis session adherence $e^{e}$ & $355(86.7)$ & $208(86.0)$ & $1.06(0.69-1.62)$ & $1.22(0.79-1.87)$ & $0.90(0.55-1.49)$ & $2.51(0.94-6.65)$ \\
\hline Patient satisfaction, n (\%) & $215(58.1)$ & $113(61.0)$ & $0.89(0.65-1.21)$ & $0.90(0.68-1.19)$ & $0.91(0.66-1.26)$ & $0.77(0.35-1.72)$ \\
\hline
\end{tabular}

${ }^{a}$ Hazard ratios are reported for mortality and transplantation. Incidence rate ratios are reported for hospitalizations and cardiovascular events. Odds ratios are reported for dialysis adherence measures. ${ }^{\mathrm{b}}$ Adjusted for age, sex, race, ICED score, serum albumin, BMI, nephrology referral time, smoking history, marital status, affectionate support and dialysis center. Potassium and phosphorus at 12 months were adjusted for the above and baseline values. Adjustment for dialysis access in hospitalization anal- yses yielded similar results in the subset of patients with this variable. ${ }^{c}$ Propensity scores were calculated using age, sex, race, marital status, smoking history, affectionate social support, ICED score, BMI, nephrology referral time, and serum albumin; and propensity score tertile analyses are also adjusted for propensity score. ${ }^{\mathrm{d}}$ Hospitalizations per person year. ${ }^{\mathrm{e}}$ Defined as missing $\leq 3 \%$ of dialysis sessions.

\section{Transplantation, Adherence Measures and Patient \\ Satisfaction Ratings}

Transplantation was no different for inpatients versus outpatients (table 2). In adjusted analysis, inpatients had $59 \%$ lower odds of having goal potassium values at 1 year; there was no difference in goal phosphate, adherence to dialysis sessions or patient satisfaction ratings.

\section{Subgroup Analyses by Referral Time and Race}

Adjusted analyses stratified by nephrology referral time revealed the protective effect of inpatient initiation on all-cause and infectious hospitalizations to be present only for those referred late; those referred early had worse outcomes (table 3). The relationship between inpatient initiation and transplantation varied by nephrology referral time (although not statistically significant), with a trend towards inpatients referred late being less likely to undergo transplantation than inpatients referred early ( $\mathrm{p}$ interaction $=0.023$ ). Those referred late were much less likely to receive a kidney transplant than those referred early. Adjusted analyses stratified by race revealed inpatient initiation to be protective against all-cause hospitalization in blacks (IRR, 0.83, 95\% CI 0.71-0.98), while whites had increased risk (IRR, 1.14, 95\% CI 1.02-1.28); p interaction $=0.043$.

\section{Sensitivity Analyses}

First, adjusted Poisson regression analysis of infectious hospitalization yielded similar findings with and without the inclusion of baseline vascular access in the model. Second, ICED scores at one year and dialysis adherence measures were examined and found to not account for differences in primary outcomes between inpatient and outpatient initiators. Third, an interaction term for race and nephrology referral time was statistically significant for several outcome analyses; however, its presence did not change the direction or magnitude of the associations. Fourth, the inclusion of time from dialysis initiation to study enrollment in adjusted analyses did not alter the primary outcome findings. Fifth, propensity score analysis revealed that the protective relationship between inpatient initiation and all-cause and infectious hospitalization was present only among those with the highest propensity to be inpatients (table 2). Finally, we found that after adding 20 additional hypothetical deaths in the first 90 days of dialysis initiation for patients started as inpatients, the unadjusted hazard ratio (HR) for mortality comparing inpatients to outpatients was 1.25 (95\% CI 1.03-1.52), but this finding became non-significant $(\mathrm{HR}=0.95$, CI $0.89-1.01)$ after adjustment for age, sex, race and comorbid disease. 
Table 3. Adjusted outcomes by location of dialysis initiation and nephrology referral time

\begin{tabular}{|c|c|c|c|}
\hline \multirow[t]{2}{*}{ Outcome measure } & \multicolumn{3}{|c|}{ Relative risk of inpatient vs. outpatient (referent) initiation ${ }^{\mathrm{a}}(95 \% \mathrm{CI})$} \\
\hline & $\begin{array}{l}\text { late referral ( } \leq 4 \text { months }) \\
(\mathrm{n}=174)\end{array}$ & $\begin{array}{l}\text { early referral (>4 months) } \\
(\mathrm{n}=361)\end{array}$ & p interaction \\
\hline Mortality & $1.23(0.67-2.26)$ & $1.13(0.82-1.57)$ & 0.304 \\
\hline All-cause hospitalization ${ }^{\mathrm{b}}$ & $0.53(0.43-0.65)$ & $1.24(1.12-1.38)$ & $<0.001$ \\
\hline Infectious hospitalization $^{\mathrm{b}}$ & $0.55(0.42-0.72)$ & $1.24(1.06-1.45)$ & $<0.001$ \\
\hline Incident cardiovascular events & $0.92(0.47-1.80)$ & $1.10(0.78-1.54)$ & 0.284 \\
\hline Transplantation & $0.21(0.03-1.52)$ & $1.63(0.71-3.74)$ & 0.023 \\
\hline \multicolumn{4}{|l|}{ Dialysis adherence measures } \\
\hline Serum potassium $\leq 5.0 \mathrm{mEq} / \mathrm{l}$ & $0.24(0.06-0.93)$ & $0.35(0.17-0.72)$ & 0.530 \\
\hline Serum phosphorus $<5.5 \mathrm{mg} / \mathrm{dl}$ & $0.78(0.27-2.25)$ & $1.18(0.83-1.68)$ & 0.498 \\
\hline Dialysis session adherence $e^{\mathcal{C}}$ & $1.94(0.54-6.87)$ & $1.23(0.73-2.09)$ & 0.629 \\
\hline Patient satisfaction & $0.90(0.39-2.05)$ & $1.02(0.73-1.40)$ & 0.943 \\
\hline
\end{tabular}

Adjusted for age, sex, race, ICD-9 score, serum albumin, BMI, smoking history, marital status, affectionate support and dialysis center. Potassium and phosphorus at 12 months were adjusted for the above and baseline values.

${ }^{a}$ Hazard ratios are reported for mortality and transplantation. Incidence rate ratios are reported for hospitalizations and cardiovascular events. Odds ratios are reported for dialysis adherence measures. ${ }^{\mathrm{b}}$ Hospitalizations per person year. ${ }^{\mathrm{c}}$ Defined as missing $\leq 3 \%$ of dialysis sessions.

\section{Discussion}

In this national prospective cohort study of incident hemodialysis patients, we found that the majority of new-onset ESRD patients were initiated on dialysis as inpatients. While there was no difference in mortality or incident cardiovascular events between inpatient and outpatient initiators, inpatient initiation had a protective association with subsequent all-cause and infectious hospitalization. However, this protection was seen only among those with the highest propensity to be inpatients, including those referred late to nephrology. Among those referred early to nephrology, inpatient initiators had a greater risk of hospitalization compared to outpatients.

Our findings suggest that inpatient dialysis initiation is a common occurrence in the US, and is likely being underestimated by the CMS Form-2728, which does not specifically include a question regarding the location of dialysis initiation. We believe that our results, ascertained by review of medical records, are a more accurate reflection of the true prevalence of inpatient initiation, which is high and carries important public health implications.

In 2004, there were 19,000 first-listed discharge diagnoses of chronic kidney disease in the US [28]; and the
Medicare expenditure for ESRD in 2005 was USD 20 billion [29]. Inpatient initiation of dialysis may be a significant contributor to this hospitalization burden and cost, although this has not been well-studied. If the percentage of US patients initiating dialysis as inpatients were reduced, it might appear that a significant amount of money could be saved. However, importantly, our results suggest that for patients with multiple comorbidities, little social support, and poor preparation for dialysis, an inpatient admission for dialysis initiation may provide an opportunity to prevent future hospitalizations, thus offsetting the initial higher cost of inpatient versus outpatient dialysis initiation. But, for those who clinically could be initiated in either setting, outpatient initiation is likely the best option.

There are several possible explanations for the protective relationship of inpatient dialysis initiation and hospitalization that we observed only among those with the highest propensity to be inpatients, including those referred late to nephrology. First, these inpatient initiators likely required intensive treatment because of limited prior nephrology care, and therefore may have received therapy such as aggressive ultrafiltration that could have helped to prevent future hospitalizations for volume overload. Second, the multidisciplinary team who often see patients when they begin dialysis during a hospitaliza- 
tion may have provided extensive education that disproportionately benefited those patients who were referred late. This education may have included details on catheter care and other infection prevention topics that could have resulted in fewer subsequent infectious hospitalizations. Pre-dialysis psychosocial and educational programs have been associated with improved clinical outcomes [30-32] and increased likelihood of planned dialysis initiation [8]; however, the effect of likely intensive in-hospital programs on those beginning dialysis as inpatients has not been established. Finally, due to the experience of illness requiring hospitalization, inpatients may have improved their health behaviors, resulting in a subsequent decreased risk of hospitalization. The trend towards better dialysis session adherence among inpatients in propensity tertile 3 (table 2 ) supports this hypothesis. Although such behavioral changes are not wellexamined in kidney disease, it has been reported that acute myocardial infarction patients may change their smoking habits because of the perception of personal vulnerability that develops following a myocardial infarction [33]. Also, it has been shown that patients who face life-threatening illnesses place higher value on health [34, 35], which could potentially lead to changes in health habits.

The finding that inpatient initiation had a protective relationship with all-cause hospitalization in blacks, while whites had increased risk, may have been related to the well-established relationship between black race and improved survival on dialysis [25] (i.e. the same factors that lead to less mortality on dialysis among blacks relative to whites may contribute to less hospitalizations as well). Alternatively, blacks may have been differentially impacted by the inpatient experience than whites. Differences in referral time did not explain this relationship.

Our study has certain limitations. First, an observational study such as ours is limited by confounding by indication for location of dialysis initiation given the lack of randomization. To address this, we considered and adjusted for multiple potential confounders. We performed propensity score adjustment as a sensitivity analysis. After these measures, we continued to find a statistically significant protective relationship between inpatient dialysis initiation and hospitalization. Nevertheless, the possibility of unmeasured confounders cannot be excluded. Second, our findings may reflect temporal trends in location of dialysis initiation, since our cohort assembled between 1995 and 1998. However, at least 3 studies outside the US have shown a similarly large percentage of patients (44-50\%) who underwent unplanned or inpatient dialysis initiation more recently (between 2003 and 2004) $[5,8,36]$, suggesting that such practices likely still occur outside of the US, and in countries with universal health care systems. Third, although the documented reasons for inpatient initiation largely represented established indications for urgent dialysis, we were lacking measures of clinical severity and appropriateness of inpatient initiation and documentation of reasons for outpatient initiation. Fourth, survival bias may have been present, but our sensitivity analysis of adding hypothetical additional deaths in the first 90 days of dialysis initiation for patients started as inpatients suggests that a crude mortality difference between inpatient and outpatient initiators is largely explained by differences in comorbid disease. We acknowledge, however, that if our sample size was larger and/or more balanced between inpatients and outpatients, we may have observed statistically significant differences in mortality. Finally, we recognize that the mean age of our study population at dialysis initiation was younger than that of patients beginning dialysis in the US today, and believe this change in dialysis population age and the increasing rate of ESRD underscores the importance of appropriate use of resources at the time of dialysis initiation.

In summary, to our knowledge, this is the first prospective US study investigating inpatient dialysis initiation and its associated outcomes. We found that inpatient hemodialysis initiation is common and is associated with several patient characteristics, including lack of social support, greater comorbid disease and late referral to nephrology. Inpatient initiation is associated with fewer subsequent hospitalizations in patients with these characteristics. For most other patients, however, inpatient initiation is associated with similar outcomes to outpatient initiation. Whether better identification of patients who might benefit from inpatient initiation of dialysis could lead to decreased health care utilization is worthy of further investigation.

\section{Acknowledgements}

We thank the patients, staff, laboratory and medical directors of the participating clinics at Dialysis Clinic, Inc. and Saint Raphael's Hospital who contributed to the study.

We thank the Cardiovascular Endpoint Committee: Bernard G. Jaar, MD, MPH; Michael J. Choi, MD; Josef Coresh, MD, PhD; Joseph A. Eustace, MD, MHS; Caroline Fox, MD, MPH; Melanie H. Katzman, MD, MHS; Michael J. Klag, MD, MPH; Yongmei 
Liu, MD, PhD; J. Craig Longenecker, MD, PhD; Michal Melamed, MD, MHS; Neil R. Powe, MD, MPH, MBA; Renuka Sothinathan, MD, MHS; Richard M. Ugarte, MD, MHS and Gayanne Yenokian, MD. Cardiovascular events adjudicators were authors Nancy E. Fink, MPH and Laura C. Plantinga, ScM.

This work was supported by grant RO1 DK 59616 from the National Institute of Diabetes and Digestive and Kidney Diseases (NIDDK), grant RO1 HL 62985 from the National Heart, Lung and Blood Institute, Bethesda, Md. and grant RO1 HS 08365 from the Agency for Health Care Research and Quality, Rockville, Md.

Dr. Crews is supported by grant 1KL2RR025006-01 from the National Center for Research Resources (NCRR), a component of the National Institutes of Health (NIH), and NIH Roadmap for Medical Research. Dr. Powe is supported, in part, by grant K24 DK 02643 from NIDDK.

\section{References}

${ }_{1}$ Kinchen KS, Sadler J, Fink N, Brookmeyer R, Klag MJ, Levey AS, Powe NR: The timing of specialist evaluation in chronic kidney disease and mortality. Ann Intern Med 2002; 137:479-486.

2 Chan MR, Dall AT, Fletcher KE, Lu N, Trivedi H: Outcomes in patients with chronic kidney disease referred late to nephrologists: a meta-analysis. Am J Med 2007;120:10631070 .

3 Nakamura S, Nakata H, Yoshihara F, Kamide K, Horio T, Nakahama H, Kawano Y: Effect of early nephrology referral on the initiation of hemodialysis and survival in patients with chronic kidney disease and cardiovascular diseases. Circ J 2007;71:511516.

4 Caskey FJ, Wordsworth S, Ben T, de Charro FT, Delcroix C, Dobronravov V, van Hamersvelt H, Henderson I, Kokolina E, Khan IH, et al: Early referral and planned initiation of dialysis: what impact on quality of life? Nephrol Dial Transplant 2003;18:13301338.

5 Castellano I, Gallego S, Labrador PJ, GomezMartino JR, Covarsi A: The start of renal replacement therapy in a Spanish department. Nefrologia 2006;26:445-451.

6 Gorriz JL, Sancho A, Pallardo LM, Amoedo ML, Martin M, Sanz P, Barril G, Selgas R, Salgueira M, Palma A, et al: Prognostic significance of programmed dialysis in patients who initiate renal substitutive treatment. Multicenter study in Spain. Nefrologia 2002; 22:49-59.

7 Marron B, Ortiz A, de Sequera P, MartinReyes G, de Arriba G, Lamas JM, Martinez Ocana JC, Arrieta J, Martinez F: Impact of end-stage renal disease care in planned dialysis start and type of renal replacement therapy a Spanish multicentre experience. Nephrol Dial Transplant 2006;21(suppl 2): ii51-ii55.

8 Buck J, Baker R, Cannaby AM, Nicholson S, Peters J, Warwick G: Why do patients known to renal services still undergo urgent dialysis initiation? A cross-sectional survey. Nephrol Dial Transplant 2007;22:3240-3245.
>9 Powe NR, Klag MJ, Sadler JH, Anderson GF, Bass EB, Briggs WA, Fink NE, Levey AS, Levin NW, Meyer KB, et al: Choices for healthy outcomes in caring for end stage renal disease. Semin Dial 1996;9:9-11.

10 Miskulin DC, Meyer KB, Athienites NV, Martin AA, Terrin N, Marsh JV, Fink NE, Coresh J, Powe NR, Klag MJ, et al: Comorbidity and other factors associated with modality selection in incident dialysis patients: the CHOICE Study. Choices for Healthy Outcomes in Caring for End-Stage Renal Disease. Am J Kidney Dis 2002;39: 324-336.

11 Sherbourne CD, Stewart AL: The MOS social support survey. Soc Sci Med 1991;32:705714.

12 Roubicek C, Brunet P, Huiart L, Thirion X, Leonetti F, Dussol B, Jaber K, Andrieu D, Ramananarivo P, Berland Y: Timing of nephrology referral: influence on mortality and morbidity. Am J Kidney Dis 2000;36: 35-41.

$\checkmark 13$ Astor BC, Eustace JA, Powe NR, Klag MJ, Fink NE, Coresh J: Type of vascular access and survival among incident hemodialysis patients: the Choices for Healthy Outcomes in Caring for ESRD (CHOICE) Study. J Am Soc Nephrol 2005; 16:1449-1455.

14 Athienites NV, Miskulin DC, Fernandez G, Bunnapradist S, Simon G, Landa M, Schmid CH, Greenfield S, Levey AS, Meyer KB: Comorbidity assessment in hemodialysis and peritoneal dialysis using the index of coexistent disease. Semin Dial 2000;13:320-326.

15 Miskulin DC, Meyer KB, Martin AA, Fink NE, Coresh J, Powe NR, Klag MJ, Levey AS: Comorbidity and its change predict survival in incident dialysis patients. Am J Kidney Dis 2003;41:149-161.

16 Levey AS, Bosch JP, Lewis JB, Greene T, Rogers N, Roth D: A more accurate method to estimate glomerular filtration rate from serum creatinine: a new prediction equation. Modification of Diet in Renal Disease Study Group. Ann Intern Med 1999;130:461-470.

17 Daugirdas JT: Second generation logarithmic estimates of single-pool variable volume $\mathrm{Kt} / \mathrm{V}$ : an analysis of error. J Am Soc Nephrol 1993;4:1205-1213.
18 Plantinga LC, Fink NE, Melamed ML, Briggs WA, Powe NR, Jaar BG: Serum phosphate levels and risk of infection in incident dialysis patients. Clin J Am Soc Nephrol 2008;3: 1398-1406.

19 Tracy RP, Lemaitre RN, Psaty BM, Ives DG, Evans RW, Cushman M, Meilahn EN, Kuller LH: Relationship of C-reactive protein to risk of cardiovascular disease in the elderly. Results from the Cardiovascular Health Study and the Rural Health Promotion Project. Arterioscler Thromb Vasc Biol 1997;17: 1121-1127.

20 Rocco MV, Yan G, Gassman J, Lewis JB, Ornt D, Weiss B, Levey AS: Comparison of causes of death using HEMO Study and HCFA endstage renal disease death notification classification systems. The National Institutes of Health-funded Hemodialysis. Health Care Financing Administration. Am J Kidney Dis 2002;39:146-153.

21 Plantinga LC, Fink NE, Sadler JH, Levey AS, Levin NW, Rubin HR, Coresh J, Klag MJ, Powe NR: Frequency of patient-physician contact and patient outcomes in hemodialysis care. J Am Soc Nephrol 2004;15:210218.

22 Unruh ML, Evans IV, Fink NE, Powe NR, Meyer KB: Skipped treatments, markers of nutritional nonadherence, and survival among incident hemodialysis patients. Am J Kidney Dis 2005;46:1107-1116.

$\checkmark 23$ Rubin HR, Jenckes M, Fink NE, Meyer K, Wu AW, Bass EB, Levin N, Powe NR: Patient's view of dialysis care: development of a taxonomy and rating of importance of different aspects of care. CHOICE study. Choices for Healthy Outcomes in Caring for ESRD. Am J Kidney Dis 1997;30:793-801.

$>24$ Greenland S, Finkle WD: A critical look at methods for handling missing covariates in epidemiologic regression analyses. Am J Epidemiol 1995;142:1255-1264.

25 Agodoa L, Eggers P: Racial and ethnic disparities in end-stage kidney failure - survival paradoxes in African-Americans. Semin Dial 2007;20:577-585. 
-26 Braitman LE, Rosenbaum PR: Rare outcomes, common treatments: analytic strategies using propensity scores. Ann Intern Med 2002;137:693-695.

27 Breslow NE, Day NE: Statistical methods in cancer research. Volume I - the analysis of case-control studies. IARC Sci Publ 1980;32: 5-338.

28 Kozak LJ, DeFrances CJ, Hall MJ: National hospital discharge survey: 2004 annual summary with detailed diagnosis and procedure data. Vital Health Stat 13 2006;162:1-209.

29 US Renal Data System: USRDS 2007 Annual Data Report. Atlas of End-Stage Renal Disease in the United States. Bethesda, National Institutes of Health, National Institute of Diabetes and Digestive and Kidney Disease, 2007.
30 Devins GM, Mendelssohn DC, Barre PE, Taub K, Binik YM: Predialysis psychoeducational intervention extends survival in CKD a 20-year follow-up. Am J Kidney Dis 2005; 46:1088-1098.

31 Goldstein M, Yassa T, Dacouris N, McFarlane P: Multidisciplinary predialysis care and morbidity and mortality of patients on dialysis. Am J Kidney Dis 2004;44:706-714.

32 Mendelssohn DC: Coping with the CKD epidemic: the promise of multidisciplinary team-based care. Nephrol Dial Transplant 2005;20:10-12.
3 Croog SH, Richards NP: Health beliefs and smoking patterns in heart patients and their wives: a longitudinal study. Am J Public Health 1977;67:921-930.

>34 Smith MS, Wallston KA, Smith CA: The development and validation of the Perceived Health Competence Scale. Health Educ Res 1995; 10:51-64.

35 Lau RR, Hartman KA, Ware JE Jr: Health as a value: methodological and theoretical considerations. Health Psychol 1986;5:25-43.

36 Watson D: Post-dialysis 'pre-dialysis' care: the cart before the horse-advanced practice nurse intervention and impact on modality selection. CANNT J 2008;18:30-33. 